\title{
Global Health Governance: Framework Convention on Tobacco Control (FCTC), the Doha Declaration, and Democratisation
}

\author{
Belinda Townsend ${ }^{1, *}$, Erik Martin ${ }^{2}$, Hans Löfgren ${ }^{1}$ and Evelyne de Leeuw ${ }^{2, *}$
}

1 School of Humanities and Social Sciences, Deakin University, 221 Burwood Highway VIC 3125, Burwood, Australia; E-Mail: hans.lofgren@deakin.edu.au

2 School of Medicine, Deakin University, 75 Pigdons Road VIC, 3216, Waurn Ponds, Australia; E-Mail: emart@deakin.edu.au

* Authors to whom correspondence should be addressed. E-Mails: bjtow@deakin.edu.au (B.T.); evelyne.deleeuw@deakin.edu.au (E.L.).

Received: 8 March 2012; in revised form: 2 May 2012 / Accepted: 15 May 2012 /

Published: 29 May 2012

\begin{abstract}
Global public health agreements are heralded as a success for the affirmation of the right to health within a complex and contested political landscape. However, the practical implementation of such agreements at the national level is often overlooked. This article outlines two radically different global health agreements: The Doha Declaration on the Trade-Related Aspects of Intellectual Property Rights (TRIPS) agreement and Public Health; and the Framework Convention on Tobacco Control (FCTC). We identify significant challenges in their implementation, particularly for low and middle income countries. Shifts in the policy network constellations around these two agreements have allowed for some positive influence by civil society. Yet industry influence at the national level constrains effective implementation and those affected by these policies have largely been left on the periphery. The broader provisions of these two agreements have been watered down by vested interests and donor conditions. We advocate for both activist and academic actors to play a significant role in highlighting the consequences of these power asymmetries. Deliberative democracy may be the key to addressing these challenges in a way that empowers those presently excluded from effective participation in the policy process.
\end{abstract}


Keywords: global health governance; deliberative democracy; implementation; international public health policy; FCTC; TRIPS; Doha Declaration on TRIPS and Public Health

\section{Introduction}

Processes of globalisation have brought about shifts in international public health policy in the last few decades. Globalisation entails awareness of the world-spanning interconnectedness of people, economy, ecology, and knowledge, with impacts positively or negatively on health. It seems that in the field of public health policy virtually every actor is engaged in a process of analysing, evaluating and (re)asserting their role in this changing arena. "Global health" refers to programs and initiatives addressing the health needs of people across many countries, rather than the concerns of particular nations. Increasingly, health problems are globally interdependent and require international or global responses including, for example, surveillance systems for early identification of epidemics. Despite obvious interdependencies, and calls for radical global change, the discourse over the governance of intellectual property rights, influenza, HIV/AIDS, and many other health-related issues, is still characterised by a divide between the different interests of the global North and South and their respective industries and domestic stakeholders [1,2].

Historically, government agencies and publicly funded international institutions provided governance of international health [3]. Typically, the movement of peoples and goods was restricted, for example, through quarantine procedures or International Health Regulations. Following its inception as an intergovernmental agency in 1948, the World Health Organisation (WHO) was for several decades the "unquestioned leader of international health" [4]. But by the late 1990s, multilateral economic institutions had established strong influence in health systems design in both developing and developed countries. The "WHOs leadership role [had] passed to the far wealthier and more influential World Bank, and the WHO's mission [had] been dispersed among other UN agencies" [5].

Global health is characterised by the interplay of many actors including governments, corporations and business groups, international institutions, philanthropic foundations and public-private partnerships, advocacy networks, NGOs and social movements. In recent decades, the most conspicuous aspect of change in global health arrangements has been and continues to be the rise of private actors. We see private actors as not only corporations, but also private philanthropic foundations and other not-for-profit entities. Among the most significant are the Bill and Melinda Gates Foundation and the Clinton Foundation. Along with these private entities, public-private partnerships (PPPs) are also important. PPPs in global health include the Global Fund to Fight AIDS, Tuberculosis and Malaria, known as the Global Fund, which has provided US\$ 22.6 billion for more than 1,000 programs in 150 countries since its creation in 2002 [6].

Contestation over what is good governance in this arena; the relative role of the state, the market and democratic citizen participation, has intensified in the same recent period that has seen the rise of private actors. Globalised challenges beyond the control of nation states and the rise of multilateral economic institutions, private actors, philanthropies and social movements have resulted in a shift in the global health governance architecture. 


\section{Two Case Studies for International Public Health Policy}

The Doha Declaration on the Trade-Related Aspects of Intellectual Property Rights (TRIPS) Agreement and Public Health and the Framework Convention on Tobacco Control are two important milestones for global health. These agreements require a whole of government approach including the involvement of non-health government departments and agencies such as trade, finance, customs, and patents. In the remainder of this paper we describe these two cases to illuminate the challenges for protecting public health within the global political economic system. In the following we have taken a concept-driven discourse mapping approach. For the FCTC we relied on concepts from the implementation research literature, and for Doha we draw more extensively on political economy. We subsequently argue for an activist approach and a research agenda that draws on deliberative or participatory models for policy development, in which all people affected by policy can play their rightful role in shaping their own health.

\subsection{The Doha Declaration on the TRIPS Agreement and Public Health}

The World Trade Organisation's Agreement (WTO) on Trade-Related Aspects of Intellectual Property Rights (TRIPS), negotiated in the 1986-1994 Uruguay Round, is the first binding agreement that extends intellectual property law into the multilateral trading system [7]. Signed by all members of the WTO, the agreement extends patent protections "in all fields of technology" and has been a source of contention between developed and developing countries. The Agreement was advocated by the United States in particular, and supported by other developed states. These countries were themselves lobbied by transnational industry networks, including the Pharmaceutical Research and Manufacturers of America (PhRMA) [8]. The requirements for implementing the agreement included extending intellectual property rights in the form of twenty year patent protection in all areas including pharmaceutical processes and products. At the signing of TRIPS, developed countries had one year to implement the requirements, with five years for developing countries and eleven years for least developed countries. However shortly after the agreement was made public, a number of civil society groups articulated concerns for the impact this agreement would have on access to medicines, in particular in the developing countries.

In response to TRIPS, a transnational civil society network emerged that coordinated with some developing countries to raise these concerns at the WTO. Such advocacy and networking led to the Doha Declaration on the TRIPS Agreement and Public Health adopted in 2001 [9], an amendment which reaffirmed flexibilities for states to protect public health, for example through the use of compulsory licensing and parallel importing. Article 4 of Doha states "The TRIPS Agreement does not and should not prevent Members from taking measures to protect public health. Accordingly, while reiterating our commitment to the TRIPS Agreement, we affirm that the Agreement can and should be interpreted and implemented in a manner supportive of WTO Members' right to protect public health and, in particular, to promote access to medicines for all" [9]. The amendment also extended transition time for TRIPS compliance for some developing countries to 2005, and for least developed countries to 2013, with the end date for introduction of pharmaceutical patents extended to January 2016. The Doha Declaration confirmed and clarified the flexibilities available to WTO member countries to 
implement TRIPS in a way consistent with public health, including their right to grant compulsory licenses for the manufacturing of drugs and to "determine the grounds upon which such licenses are granted". Paragraph 6 of the Doha Declaration was amended in 2003 to enable countries with little to no manufacturing capability to import drugs manufactured elsewhere under compulsory licensing.

The Doha Declaration is commonly viewed as the breakthrough point for an "access to medicines" norm, defined as "shared expectations about appropriate behaviour held by a community of actors" [10]. Since 2004, 52 countries have made use of the flexibilities sanctioned at Doha to authorise generic imports of patented drugs for HIV/AIDS, or have negotiated a reduced price for these drugs [11]. Yet despite global commitments, it is apparent that "access to medicines" is an ambiguous policy objective, meaning different things to different actors. The limited impact of this agreement on the availability and accessibility of medicines for developing countries is well documented [12-15]. A United Nations Millennium Development Goal task force report in 2008 revealed that the price of medicine is still out of reach for many in developing countries, with some generics in the public and private sectors found to be priced on average 250 per cent and 610 per cent more than the estimated international reference price ${ }^{1}$ in countries surveyed [16]. As will be discussed below, states face a number of similar challenges in protecting public health, and these challenges represent broader issues at the core of the political economy of global health governance.

\subsection{The Framework Convention on Tobacco Control}

The Framework Convention on Tobacco Control (FCTC) is an international treaty developed under the auspices of the World Health Organisation in response to the globalisation of the tobacco epidemic which has spread to the developing world [17]. Increased empirical evidence of the adverse effects of tobacco use, along with sustained pressure from researchers and civil society groups, and leadership from elites, has resulted in the elevation of tobacco control to the forefront of the global health agenda. The FCTC was negotiated between 1999 and 2003 and as the first international treaty for public health is often described as a marked success. The negotiations were primarily undertaken by governments, but civil society organisations played a significant role in influencing policy decisions [18]. The FCTC entered into force in 2005, and as of February 2012, the treaty has been ratified by 174 countries covering 87.4 per cent of the world's population [19]. Despite such an achievement, the negotiations of the treaty were not immune to the interests of tobacco companies and unwilling governments, as the treaty was "watered down" in its ability to address key concerns. For example, an explicit FCTC trade provision was removed [20], the language was weakened and terms made more flexible [21], and the final agreement allowed exceptions on total advertising bans for countries claiming constitutional impediments [22]. To meet the obligations under this international treaty, parties must implement a multitude of tobacco control provisions to reduce both the demand and supply of tobacco. Among many other provisions, this includes demand measures such as taxes on tobacco products, health warnings on cigarette packaging, bans on tobacco advertising, promotion and sponsorship, and supply measures including support for economically viable alternatives to growing tobacco. These provisions

\footnotetext{
${ }^{1}$ International Reference Pricing (IRP) compares the prices for the same medicine in different countries and the reference price for that medicine is determined by an arbitrary statistical calculation (i.e., average of all, average of lowest 3 countries) [23].
} 
vary in the extent of their implementation. For example, guidelines and time-bound deadlines have been developed for the provisions for smoke-free environments, packaging and labelling, and bans on advertising, promotion and sponsorship. Time-bound commitments are yet to be developed for some other provisions.

That the FCTC has created some momentum for national governments to develop comprehensive tobacco control legislation was confirmed through our research of developments in several Pacific Island nations. In its 2010 global report on FCTC implementation the WHO stated that after five years of implementation, global progress is visible. It was self-reported by participating states that more than half of FCTC provisions had attracted high implementation rates [24]. It is also stated that implementation rates vary between different policy measures and the analysis of implementation of time-bound commitments suggests mixed results [24]. Despite its heralded success in the public health realm, developing countries in particular face significant challenges in the implementation of the FCTC. In relation to harnessing political will, some research suggests that there is a lack of civil society involvement [25,26], as well as competing concerns for resourcing such as the Millennium Development Goals, access to health care and poverty alleviation [27]. Furthermore, limited policy implementation capacity in many developing nations presents itself as a significant barrier [28]. A critical challenge is the limited funding available for both communicable and non-communicable diseases in low-income countries [29]. It should also be noted that global public investments in tobacco control are "extremely small compared with both corporate profits and government revenues from cigarette sales" [30]. Effective implementation and enforcement of the Convention in many developing countries requires that resources be transferred from other domestic public policy programs or become reliant upon overseas aid. In a similar critique to that of Calain in his study of the International Health Regulation requirements in developing countries, the FCTC, despite its successes, may too "have been conceived in neglect of fragile health systems" [31]. The challenges for implementing tobacco control are also indicative of common issues in the broader political and economic architecture of global health governance.

\section{Challenges for Implementing Global Health Agreements: The Architecture of Global Health}

Following the above two case studies we will continue our analysis around three arguments:

\subsection{Global Funding Arrangements are Unsustainable under the Current Architecture}

In light of funding constraints to provide medicines and to curtail tobacco use, we have seen private actors such as Bloomberg Philanthropies (for the FCTC) and the Bill and Melinda Gates Foundation (for both medicines and tobacco control) gain widespread acceptance as sources of funding. Similarly, public private partnerships such as the Global Fund and the GAVI Alliance have arisen as major fundraisers for the provision of essential medicines and vaccines. Yet developing countries face significant funding constraints to the extent that they rely on unsustainable private sources of funding to implement tobacco control and provide medicines to their citizens.

That this reliance is unsustainable is evident from the 2011 funding shortfalls at the Global Fund, a large donor for HIV/AIDS, Tuberculosis and Malaria treatment [32]. This funding shortfall has resulted in no scale-up of HIV treatment through the Fund until at least 2014. According to the NGO Medicines 
Sans Frontières (MSF), Kenya, Lesotho and South Africa "weren't eligible to apply for funding from Round 11 because of lacking funding. In these countries, HIV treatment coverage (currently) lies at 52 per cent, 66 per cent and 49 per cent, respectively" [33]. Thus the real implications of the funding shortfalls of global partnerships are matters of life and death. Similarly, in the absence of sufficient WHO and government funding for tobacco control, non-state actors such as Bloomberg Philanthropies and the Bill and Melinda Gates Foundation have attempted to fill this void by providing support for tobacco control in low income countries. It is unsatisfactory for essential public health programs to depend on funding by a few private philanthropic organisations, particularly in an era in which global economic uncertainty looms large.

\subsection{Funding Conditions Narrow Provisions to Protect Public Health}

The FCTC has provisions to address both the supply and demand of tobacco. Yet evidence collected by one author from fieldwork in the Pacific islands reveals that the implementation of the FCTC addresses the demand side of intervention while neglecting to comprehensively address supply. The MPOWER policy package introduced to assist developing countries to implement the FCTC is sponsored by Bloomberg Philanthropies. The components of MPOWER include: "Monitor tobacco use and the policies to prevent it; Protect people from tobacco smoke; Offer people help to quit tobacco use; Warn about the dangers of tobacco; Enforce bans on tobacco advertising, promotion and sponsorship, and; Raise taxes on tobacco" [34]. This package gives no attention to the supply of tobacco. Despite good intentions, large-scale financial support for MPOWER by Bloomberg and the Bill and Melinda Gates Foundation [35] risks diverting attention and resources from the broader mandate of the FCTC to address the supply of tobacco.

Similarly, despite the flexibilities in TRIPS, confirmed in the Doha Declaration, philanthropy and global public private partnerships are now central to the procurement of essential medicines through drug donation programs and external aid for purchasing medicines. Developing countries are by no means making full and effective use of the flexibilities for protecting health. A recent survey of the use of compulsory licenses (CLs) since 1995 found that the use of CLs has diminished since 2006. Prior to that year, most CLs involved drugs for HIV/AIDS and occurred in upper-middle-income countries (UMICs), "few involved communicable disease and none occurred in least or low-income countries" [36].

Most public private partnerships for the provision of medicines do not address the structural issues at the core of medicines inaccessibility, including the cost and direction of research and development, and the inefficient patent system. This reflects similar critiques that prominent funding partnerships have "turned to a narrowly conceived understanding of health as a product of technical interventions divorced from economic, social and political contexts" [37].

It appears that these semi-corporate efforts lack a systemic and politically informed perspective. They cherish technological and behavioural interventions and investments over critical shifts in governance. As Birn argues, these programmes are devoid of long-term, sustainable, socio-political support mechanisms [37]. In the case of tobacco, restricting attention and resources to demand-side interventions could be related to the concept of "lifestyle drift" [38-40], where governments commit to addressing "wider social determinants of health, but end up instigating narrow lifestyle interventions" to affect individual behaviour [41]. This could also be said about dominant financial and partnership 
approaches to "access to medicines", which pay too little attention to the social determinants that contribute towards illness. However, such critiques are beyond the scope of this article as our focus is on two global agreements and their implementation.

\subsection{The Negotiation and Implementation of International Public Health Agreements have been Unduly} Influenced by Vested Interests

Globalisation has introduced new powerful actors into network constellations in health. The globalisation of tobacco use spans several centuries, although last century saw an expansion of this process where a handful of multinational tobacco corporations (and a Chinese state-owned monopoly) came to dominate the global market. Corporate mergers in pharmaceuticals have also led to dominance in this sector by a small number of large transnational companies. Such companies exert, or seek to exert a strong influence on international and domestic public policy. Despite the WHO excluding tobacco companies from involvement in the FCTC negotiation process the FCTC itself has not been free of undue influence by the industry in the negotiation of the treaty [20-22]. Indeed, vested interests contributed to a weakening of the terminology and focus of the FCTC. Firstly, the existence of state owned tobacco companies $[42,43]$ present a vested interest that the WHO is unable to mitigate. This can be seen through “Japan's success in arguing for optional language in the treaty", where the Japanese government owns a substantial proportion of Japan Tobacco Inc. [21]. Gruning et al. [22] also explain that "Germany played a major role in the tobacco industry's efforts to undermine the FCTC". Germany's position "served to protect the interests of the tobacco industry and mobilised other negotiating parties in the industry's fight against a strong FCTC" [22]. It has also been suggested that "international factors, together with tobacco industry activities at the country level hampered development of international norms in trade and health in the FCTC" [20]. Collin also argues that the FCTC fails to adequately address trade, a major driver of the tobacco pandemic, where "health objectives have been subordinated to core principles of foreign and economic policy" [44].

In looking beyond the negotiation of the FCTC and the treaty text itself, the implementation of the FCTC is largely conducted at the national level. Despite a provision articulating that health policy should not be influenced by the tobacco industry, there are many examples of the industry seeking to influence or undermine national health policies in countries that have ratified the FCTC. Implementation of the FCTC requires a whole-of-government approach inclusive of areas of government outside of health such as finance, trade and customs. These different arms of government have different priorities and can be more vulnerable to lobbying and influence from the tobacco industry. After investigating the FCTC implementation in several Pacific Islands, one of the authors found that national governments are still approached by representatives of the industry seeking to influence decisions relating to tobacco control. In Australia, the Liberal party, one of two major political parties, still receives donations from the tobacco industry, and the industry has spent an estimated 20 million dollars (AUD) in advertising against the Australian Government's plain packaging bill [45]. There would no doubt be many other examples of the tobacco industry seeking to influence decisions at the national level, despite the FCTC ratification and its provisions.

While Doha confirmed beyond doubt flexibilities under TRIPS available to protect health, developing countries continue to face corporate litigation by pharmaceutical companies, as well as pressures in 
bilateral and regional trade negotiations to extend intellectual property rights beyond the requirements of TRIPS. An example of corporate litigation is the case of Novartis in India, which after failing at the India Patent Office and in the High Court, has gone to the Supreme Court in an attempt to overturn Section 3(d) of India's 2005 Patent Act. This section states that a "new use for a known substance" is not an invention and thus not patentable if it fails to demonstrate enhanced efficacy [46,47]. India has so far "rejected the Novartis patent application for the anti-cancer drug imatinib mesylate on the grounds that it lacked novelty, was obvious and un-patentable under Section 3(d)" [48]. The case was to be heard by the Supreme Court in July 2012 and its outcome could have global repercussions, undermining the role of India as the "pharmacy of the developing world". India is the main supplier to the MSF and others international provides of essential medicines. Notably, "80 per cent of antiretrovirals (ARVs) procured by MSF are purchased in India, 89 per cent of the generic ARV's approved by the US Food and Drug Administration for PEPFAR are from India, and 70 per cent of the ARV treatment purchased by UNICEF, the International Development Association, the Global Fund (GFATM) and the Clinton Foundation since July 2005 have come from Indian suppliers" [49].

An important development is that the Indian generic drug company Natco Pharma in March 2012 was successful in gaining India's first compulsory license for the production and supply of the patented anti-cancer drug sorafenib, marketed by the German multinational Bayer as Nexavar. Bayer's version of this drug costs Rs 280,000 (approximately \$5,600) a month, an astronomical figure for almost all Indian households. Natco will sell the same drug at 3 per cent of this price, whilst paying a license fee and still making a profit [50]. The CL was issued essentially on the grounds that Bayer's price is exorbitant. Bayer also does not manufacture the drug in India and imports in such small volumes that only a tiny fraction of potential patients could benefit. The Controller General of Patents concluded that the drug "was not bought by the public due to only one reason, that is, its price was not reasonably affordable to them" [50]. This decision in favour of Natco sets a very important precedent for possible CLs on other patented products sold at unaffordable prices.

India's Patent Act, which affirms TRIPS flexibilities for public health, has set a precedent. In November 2011, the Working Group on Intellectual Property of the Brazilian Network for the Integrations of People (REPRIP), a network of civil society organisations, opposed the patent application by the US pharmaceutical company Abbott for the heat-stable versions of the drug lopinavir/ritonavir (LPV/r), which is a key HIV drug recommended by the World Health Organisation [47]. "The opposition is based on the fact that the applications lack novelty and an inventive step, being merely a combination of existing drugs, and known technologies for producing heat-stable formulations, respectively" [47]. If Novartis were to successfully overturn aspects of the Indian Patent Act, this could potentially set a precedent in which these lifesaving medicines would be out of reach for many in dire need. In Brazil's case, a patent to Abbott would extend the monopoly of LPV/r to 2024, threatening expanded access to the drug. The battle between multinational pharmaceutical companies and some developing countries in their attempts to provide health resonates with Baum and Sanders critique of transnational corporations (TNCs) in the food industry [39]. In their critique of food and agricultural TNCs, the authors argue that the "combination of producer subsidies, global trade liberalization and strengthened property rights has given increasing power to the corporate food industry and undermined national food security in many countries" [39]. 
As noted, challenges facing developing countries in their protection of public health include bilateral and multi-lateral trade agreements that reflect the interests of Northern pharmaceutical companies. Such agreements are known as "TRIPS plus", that is, intellectual property protection more extensive than required by TRIPS. Such provisions "extend patent terms in certain circumstances, establish a link between drug registration and patents, (and) grants exclusive rights with respect to test data" [15]. Leaked documents of a proposed India-EU Free Trade Agreement (FTA) reveal negotiations for greater intellectual property protection then required by TRIPS [51]. In response, the European Union has confirmed that patent extension and "data exclusivity" (the protection of data submitted for marketing approval) are on the table for negotiation, while at the same time stating commitment to "access to medicines" [52]. India has recently rejected data exclusivity, which extends the period of monopoly supply, delaying the market entry of cheaper generics, yet concerns still remain for the outcome of this FTA [53]. It is apparent that the rhetoric around "access to medicines" is an ambiguous aim meaning different things to the actors involved [54]. "Access to medicines" can accommodate a range of diverse competing interests, where discourses seek to protect, transform, or do away with the global intellectual property rights system.

Leaked texts of the Trans Pacific Partnership Agreement (TPPA) currently under negotiation also reveal extensive IP protections beyond TRIPS and "TRIPS plus" FTAs [55]. The TPPA is under negotiation between the US, Australia, New Zealand, Singapore, Brunei, Chile, Malaysia, Peru, and Vietnam. Draft texts have included rules on government procurement which can impact on government purchasing of medicines. The inclusion of an Investment State Dispute Settlement mechanism could enable corporations (including the multinationals in the tobacco industry) to sue governments seeking to implement policy measures to protect public health [56]. The negotiations are set to be finalised in 2012 . The negotiation of these trade agreements highlight significant tensions between commercial interests and health globally, which can also take place at the national level, where for example, a Ministry of Trade can often have different priorities to that of the Ministry of Health.

\section{Reconnecting the Disconnected}

Our analysis confirms that corporate interests exercise significant influence in global health and while civil society movements have emerged, "those affected" are often on the periphery of policy decision making. The citizen is underrepresented in the current political economic structure reflected in the North South divide. This exclusion is the concern of political theorists such as John Dryzek [57] who explore ways of making the global system more democratic and alternatives to liberal democracy that provide more democratic depth and authenticity.

It should be acknowledged that civil society organisations focused on public health and tobacco control are active at local, national and global levels. At a global level civil society organisations did play a significant role in the negotiation of the FCTC through the Framework Convention Alliance. This organisation used a range of mobilising strategies including international networking, wide distribution of a newsletter, shaming of the tobacco industry, and general advocacy to influence policy positions [18]. Similarly, in response to TRIPS and in advocacy at Doha, a transnational civil society network maintained pressure in campaigns for access to medicines and health for all. An example of a very real bottom up demonstration of a globally networked grassroots health movement is the People's 
Health Movement (PHM) [58]. The PHM helped initiate the Global Health Watch aimed at mobilising civil society around an alternative health report [59]. However civil society organisations have fewer resources than the multinational tobacco and pharmaceutical companies and tend to operate on the periphery of public health policymaking. Widening the inclusion of people more generally in policy decision processes at various levels that directly impact on their lives may mitigate the challenges that countries face in global governance.

We suggest that deliberative democracy may hold an important key to global inclusion and enhancing the quality and equity of policy in global health. Deliberative democracy aims to bring "those affected" into the decision making processes that determine the policies which affect their wellbeing. Common to these approaches is active participation, defined by Cohen et al. as "a relation based on partnership with government, in which citizens actively engage in the policy making process. It acknowledges a role for citizens in proposing policy options and shaping the policy dialogue" [60]. The aim is to provide an arena free from coercion and manipulation in which opportunities for participation exist for all affected [57,61]. In this context, debate is framed around the common good through public reasoning rather than self-interests [61]. Material presented for deliberation is balanced and informed by a range of experts and designed by social scientists with the aim to remove the kind of coercive manipulation by industry and skewing evident in mainstream media.

Deliberative democracy can enable an "opening up" of the policy debate and provide greater space for the kinds of arguments (the right to health, health for all) that made the development of the FCTC and the Doha amendments to TRIPS possible. These arguments are likely to be weakly represented in the domestic setting where implementation of these agreements is difficult due to many factors that we have touched upon, including lack of resources, administrative incapacity, industry influence, and donor conditionalities. For example, in the case of the FCTC, articles that address the supply of tobacco, such as article 17 [17]; the provision of support for economically viable alternative activities, are important for low income farmers currently reliant upon farming tobacco, but the vast majority of parties have thus far sidelined the implementation of this provision. In countries where a large proportion of the population is unable to afford medicines, the use of Doha flexibilities is necessary, and would be likely to gain stronger support. The deliberation of values that occurs in deliberative democracy offers a way to challenge the present narrow conception of health in international policy making that is supported by an undue emphasis on market mechanisms, and to correct "the science blind spot that science and technology know health only in instrumental terms" [62]. This can mitigate against the problem of industry influence.

Deliberative polling ${ }^{\odot}$ is a method of conducting deliberative democracy that has been successfully developed and implemented for many issues in many countries. Deliberative polling ${ }^{\odot}$ follows the method of social science in which the aim is to have a deliberating sample statistically representative of the general population. This would include representatives of those groups on the periphery or traditionally excluded from policy making, including women, low socioeconomic groups, and ethnic minorities. This is important in health as tobacco smoking rates are associated with low socio-economic status in many countries, and represent an increasing burden in developing countries [63]. Accessibility of medicines is also an issue for the poor; in both developed countries where public insurance is sometimes inadequate (and largely absent in the US), and in low-income countries in which large sections of the population cannot afford patented drugs, or even any modern drugs at all. 
This is not esoteric or the fantasy of a few but has been implemented in different forms in many countries. The principles of deliberative democratic theory have been operationalised for a number of issues including the Euro in Denmark [64], town planning in local government in China [65], utilities in Texas, and health care in Canada [66]. The outcomes of such experiences support the contention that individuals are amenable to changing their opinion, show considerable change in opinion on about 70 per cent on all items asked [61], significantly increase their knowledge, and gain an improved ability to form reasoned opinion in the collective interest $[61,66]$.

Box 1. The CaliforniaSpeaks Project.

\begin{abstract}
The 2007 CaliforniaSpeaks project on health care reform is an example of an attempt at deliberative democracy [67]. CaliforniaSpeaks involved 3500 citizens recruited with representative sampling to deliberate and evaluate health care reform proposals under consideration by state leaders. The impact of deliberation on the participants was evident. Of note, the deliberations produced priority values to guide the health care reform. These included that "health should be affordable to all, everyone should have access, put people before profit, and make wellness and prevention a priority" [67]. Also, participants expanded the agenda to include a single payer system option, one not included by the Governor or the legislative leadership. Furthermore, opinion surveys estimated that nearly one in two participants changed their opinions on the policy reform options [68], illustrating the capacity of ordinary citizens to change their view through reasoned, informed discussion. Interestingly, 63 per cent of participants supported "prevention and wellness" measures which included options such as targeting tobacco use reduction [69]. Participants were also much more likely to engage in a range of political actions on healthcare, with 40 per cent of participants reporting that they contacted a political leader after the deliberation day (in comparison to a control group at 12 per cent) [68]. This demonstrates the potential empowering aspect of deliberation. However, as mentioned above, the process was not unproblematic and must be further improved. Issues that arose included a low turnout of the minority Latino population and the neglect to include a single payer system as an option in the original program. While an assessment post deliberation found that the legislature had moved closer to the public priorities on a number of proposals, the issue of a single payer system was an exception.
\end{abstract}

There is much evidence to support the view that deliberative democracy will assist in prioritising public health over private interests. Commers argues that "lay" communities have a profound understanding of the social determinants of health, but that these understandings are mis- and under- represented in the media and political discourse [70]. The huge burden of tobacco use on health has been well recognised for almost sixty years, and evidence shows that most people who use tobacco want to quit when informed of the health risks [31]. In a study of parliamentary debates in New South Wales (Australia), Hooker and Chapman [71] argue that "the overall evolution of tobacco control policy was shaped by legislators commitment to the ideals of deliberative democracy". A moral discourse, constructed with reference to personal anecdote was mobilized by MPs to exclude the tobacco industry's arguments. In this case it should be noted that it was deliberation amongst MPs that was deliberative, but this was not deliberative democracy in the sense of our argument and as exemplified above. The empirical evidence, supported by strong theory, suggests that if "those affected" were to be more empowered through an "opening up" of debate and the policy process, this could lead to more effective implementation of health policy. One of the author's findings from FCTC 
implementation research in several Pacific island nations suggests that stronger community engagement would enhance the conditions for a successful and broad FCTC implementation.

Deliberation without democracy is problematic. Some global actors including the Global Fund and World Bank have sought to enhance deliberation in governance. Yet studies of these processes and outcomes reveal problems [72,73]. The case studies point to power asymmetries in the global governance architecture whereby attempts for distributive justice are curtailed or circumvented. To claim to be deliberative is not enough-democracy is necessary. Of course it is difficult to speculate on how deliberative democracy could operate at the global level with some seven billion affected individuals. However the results from national and regional experiments indicate that deliberative democracy is worth exploring in more depth. Further, while governments can choose to ignore the outcomes of a citizen forum, this may bring about a loss of legitimacy and potential voter backlash at the next election. Deliberative democracy through involving "those affected" may hold some potential in alleviating some of the issues identified.

\section{Conclusion}

We have described the governance constraints which pose significant problems for implementing policies that protect health in the areas of tobacco control and access to medicines. It is widely recognised that to adequately address the social determinants of health, a human rights and public goods approach is required, with an independent World Health Organisation, a voice for the marginalised and increased resources for low and middle income countries [1,55,74-76]. Yet the realisation of these proposals has been difficult to initiate and attain, for reasons alluded to in our case studies. While both the Doha Declaration and the FCTC are promoted as successes for public health, low and middle income countries have faced many implementation challenges. We call for more experimental research around policy processes that more actively engage people in the decision making that relates to their health. Deliberative democracy may provide an avenue to substantively include the voice of "those affected", potentially shifting the discourse to one where health is a priority.

\section{References}

1. Lee, K.; Fidler, D. Avian and pandemic influenza: Progress and problems with global health governance. Glob. Public Health 2007, 2, 215-234.

2. Bartsch, S.; Kohlmorgen, L. The Role of Civil Society Organisations in Global Health Governance. In Global Health Governance and the Fight Against HIV/AIDS; Hein, W., Bartsch, S., Kohlmorgen, L., Eds.; Palgrave Macmillan: Hampshire, UK, 2007; p. 92-118.

3. Ng, N.Y.; Ruger, J.P. Global health governance at a crossroads. Glob. Health Gov. 2011, 3, 1-36.

4. Brown, T.M.; Cueto, M.; Fee, E. The World Health Organization and the transition from "International" to "Global" public health. Am. J. Public Health 2006, 96, 62-72.

5. Silver, G.A. International health services need an interorganizational policy. Am. J. Public Health 1998, 88, 727-729. 
6. The Global Fund to Fight HIV/AIDS, Tuberculosis and Malaria. Global Fund Welcomes US Secretary of State Hillary Clinton support for Global Fund; The Global Fund to Fight HIV/AIDS, Tuberculosis and Malaria: Geneva, Switzerland, 9 November 2011. Available online: http://www.theglobalfund.org/en/mediacenter/pressreleases/2011-11-09_Global_Fund_ welcomes_U_S_Secretary_of_State_Hillary_Clinton_support_for_Global_Fund/ (accessed on 4 March 2012).

7. World Trade Organisation. Understanding the WTO: Intellectual Property: Protection and Enforcement; World Trade Organisation: Geneva, Switzerland, 2011. Available online: http://www.wto.org/english/thewto_e/whatis_e/tif_e/agrm7_e.htm (acccessed on 12th December 2011).

8. Sell, S.K. Trips-plus free trade agreements and access to medicines. Liverp. Law Rev. 2007, 28, 41-75.

9. World Trade Organization. Declaration on the TRIPS Agreement and Public Health; World Trade Organization: Geneva, Switzerland, 2001. Available online: http://www.wto.org/english/thewto_ e/minist_e/min01_e/mindecl_trips_e.htm (accessed on September 2010).

10. Finnemore, M. Norms, culture, and world politics: Insights from sociology's institutionalism. Int. Org. 1996, 50, 325-347.

11. 't Hoen, E. The Global Politics of Pharmaceutical Monopoly Power: Drug Patents, Access, Innovation and the Application of the WTO Doha Declaration on TRIPS and Public Health; AMB Publishers: Diemen, The Netherlands, 2009.

12. 't Hoen, E. TRIPS, pharmaceutical patents, and access to essential medicines. Chic. J. Int. Law 2002, 3, 27-46.

13. Sell, S.A. Private Power, Public Law: The Globalisation of Intellectual Property Rights; Cambridge University Press: Cambridge, UK, 2003.

14. Drahos, P. Four lessons for developing countries from the trade negotiations over access to medicines. Liverp. Law Rev. 2007, 28, 11-39.

15. Correa, C.M. Intellectual Property Rights and Inequalities in Health Outcomes, WHO Commission on Social Determinants of Health. In Globalization Knowledge Network Research Paper; Institute of Population Health, University of Ottawa: Ottawa, Canada, 2007; pp. 1-28.

16. Millennium Development Goal Gap Task Force. In Strengthening the Global Partnership for Development in a Time of Crisis; United Nations: Geneva, Switzerland, 2009; p. 50.

17. World Health Organisation (WHO). WHO Framework Convention on Tobacco Control; World Health Organisation: Geneva, Switzerland, 2005.

18. Mamadu, H.M.; Glantz, S.A. Civil society and the negotiation of the Framework Convention on Tobacco Control. Glob. Public Health 2009, 4, 150-168.

19. Framework Convention Alliance. FCA Membership Directory. Available online: http://www.fctc.org/index.php?option=com_sobi2\&catid=8\&Itemid=26 (accessed on 27 February 2012).

20. Mamadu, H.M.; Hammond, R.; Glantz, S.A. International trade versus public health during the FCTC negotiations, 1999-2003. Tob. Control 2011, 20, 1-10.

21. Assunta, M.; Chapman, S. Health treaty dilution: A case study of Japan's influence on the language of the WHO Framework Convention on Tobacco Control. J Epidemiol. Commun. Health 2006, 60, 751-756. 
22. Grüning, T.; Weishaar, H.; Collin, J.; Gilmore, A.B. Tobacco industry attempts to influence and use the German government to undermine the WHO Framework Convention on Tobacco Control. Tob. Control 2012, 21, 30-38.

23. Innovative Medicines South Africa (IMSA). In Referencing Pricing-Background Informtion and IMSA Position; IMSA: Houghton, South Africa, N.D; pp. 1-4. Available online: http://www.imsa.org.za/files/Library/IMSA\%20Position\%20Statements\%20and\%20Issues(1)/IM SA\% 20Position\%20on\%20Reference\%20Pricing.pdf (accessed on 8 March 2012).

24. World Health Organisation (WHO). Global Progress Report on Implementation of the WHOFramework Convention on Tobacco Control; World Health Organisation: Geneva, Switzerland, 2010.

25. Albuja, S.; Daynard, R.A. The Framework Convention on Tobacco Control and the adoption of domestic tobacco control policies: The Ecaudorian experience. Tob. Control 2009, 18, 18-21.

26. Sussman, S.; Pokhrel, P.; Black, D.; Kohrman, M.; Hamann, S.; Vateesatokit, P.; Nsimba, S.E.D. Tobacco control in developing countries: Tanzania, Nepal, China and Thailand as examples. Nicotone Tob. Res. 2007, 9, S447-S457.

27. Lin, V. The Framework Convention on Tobacco Control and health promotion: strengthening the ties. Global Health Promotion 2010, 17, 76-80.

28. Wipfli, H.; Stillman, F.; Tamplin, S.; Luiza de Costa e Silva, V. Achieving the Framework Convention on Tobacco Control's potential by investing in national capacity. Tob. Control 2004, 13, 433-437.

29. Ross, H.; Stoklosa, M. Development assistance for global tobacco control. Tob. Control 2011, doi:10.1136/tc.2011.043380, 1-6.

30. Callard, C. Follow the Money: How the billions of dollars that flow from smokers in poor nations to companies in rich nations greatly exceed funding for global tobacco control and what might be done about it. Tob. Control 2010, 19, 285-290.

31. Calain, P. From the field side of the binoculars: A different view on global public health surveillance. Health Policy Plan. 2007, 22, 13-20.

32. The Global Fund to Fight HIV/AIDS, Tuberculosis and Malaria. In The Global Fund Adopts New Strategy to Save 10 Million Lives by 2016; The Global Fund to Fight HIV/AIDS, Tuberculosis and Malaria: Geneva, Switzerland, 2011.

33. Médecins Sans Frontières (MSF). MSF Response to Unprecedented Decision to Cancel Funding Round of the Global Fund to Fight AIDS, TB and Malaria; Médecins Sans Frontières: Geneva, Switzerland, 2011.

34. World Health Organisation (WHO). WHO Report on the Global Tobacco Epidemic; World Health Organisation: Geneva, Switzerland, 2009.

35. Bloomberg Philanthropies and Bill and Melinda Gates Foundation. Michael Bloomberg and Bill Gates Join to Combat Global Tobacco Epidemic;Bloomberg Philanthropies and Bill and Melinda Gates Foundation: New York, NY, USA, 23 July 2008. Available online: http://www.tobaccofreecenter.org/files/pdfs/en/

Bloomberg-GatesReleaseFinal.pdf (accessed on 8 December 2011).

36. Beall, R.; Kuhn, R. Trends in compulsory licensing of pharmceuticals since the Doha declaration: A database analysis. PLoS Med. 2012, 9, e1001154, doi:10.1371/journal.pmed.1001154. 
37. Birn, A. Gate's grandest challenge: Transcending technology as public health ideology. Lancet 2005, 366, 514-519.

38. Baum, F. From Norm to Eric: Avoiding lifestyle drift in Australian health policy. Aust. N. Z. J. Public Health 2011, 35, 404-406.

39. Baum, F.E.; Sanders, D.M. Ottawa 25 years on: A more radical agenda for health equity is still required. Health Promot. Int. 2011, 26, 253-257.

40. De Leeuw, E.; Clavier, C. Healthy public in all policies. Health Promot. Int. 2011, 26, 237-244.

41. Hunter, D.J.; Popay, J.; Tannahill, C.; Whitehead, M. Getting to grips with health inequalities at last? Marmot Review calls for renewed action to create a fairer society. $B M J \mathbf{2 0 1 0}, 340,323-324$.

42. Barraclough, S.; Marrow, M. The political economy of tobacco and poverty alleviation in Southeast Asia: Contradictions in the role of the state. Glob. Health Promot. 2010, 17, 40-50.

43. Lv, J.; Su, M.; Hong, Z.; Zhang, T.; Wang, B.; Li, M. Implementation of the WHO Framework Convention on Tobacco Control in mainland China. Tob. Control 2011, 20, 309-314.

44. Collin, J. Global health, equity and the WHO Framework Convention on Tobacco Control. Glob. Health Promot. 2010, 17, 73-75.

45. Chapman, S.; Freeman, B. Feature: From brand to bland-The demise of cigarette packaging. BMJ 2011, 343, doi:10.1136/bmj.d4376.

46. Basheer, S. India's tryst with TRIPS: The patents amendment act 2005. Indian J. Law Technol. 2006, $1,15-46$.

47. Médecins Sans Frontières (MSF). Brazilians Demand Greater Access to Crucial HIV Drug; Médecins Sans Frontières: Geneva, Switzerland, 2011.

48. Médecins Sans Frontières (MSF). What Future for India's Patent Act? Novartis vs. Union of India; Médecins Sans Frontières: Geneva, Switzerland, 2011.

49. Médecins Sans Frontières (MSF). Examples of the Importance of India as the "Pharmacy of the Developing World”; Médecins Sans Frontières: Geneva, Switerland, 2011.

50. Srinivasan, S. The Compulsory Licence for Nexavar. Econ. Polit Weekly 2012, 14, 10-13. Available online: http://www.epw.org.in/epw/uploads/articles/17300.pdf (accessed on 25 April 2012).

51. Bilaterals.org. EU-India FTA-Consultation Draft on IPR Chapter (April 2010). Available online: http://www.bilaterals.org/spip.php?article17290 (accessed on 11 September 2011).

52. De Gucht, K. Letter to Executive Director MSF Mr. von Schoen-Angerer; Médecins Sans Frontières: Geneva, Switzerland, 2010. Available online: http://msfaccess.org/sites/default/files/ MSF_assets/Access/Docs/ACCESS_letter_ECTradeCommisioner_Gucht_ENG_2010.pdf (accessed on 12 September 2011).

53. Médecins Sans Frontières (MSF). India Says 'No' to Policy that Would Block Access to Affordable Medicine; Médecins Sans Frontières: Geneva, Switzerland, 2011.

54. Stone, D.A. Policy Paradox: The Art of Political Decision Making; Norton: New York, NY, USA, 2002. 
55. Rosenberg, S. Comparative Chart of Pharmaceutical Patent and Data Provisions in the TRIPS Agreement, Free Trade Agreements between Trans-Pacific FTA Negotiating Countries and the U.S. and the U.S. Proposal to the Trans-Pacific FTA 2011. Public Citizen: Washington, DC, USA, 2 December 2011. Available online: http://www.citizen.org/Page.aspx?pid=5231 (accessed on 8 March 2012).

56. Citizen Trade Campaign. Leaked Trans-Pacific FTA Texts Reveal U.S. Undermining Access to Medicine; Citizen Trade Campaign: Washington, DC, USA, 2011. Available online: http://www.citizenstrade.org/ctc/blog/2011/10/22/leaked-trans-pacific-fta-texts-reveal-u-sundermining-access-to-medicine/ (accessed on 8 March 2012).

57. Dryzek, J.S. Deliberative Global Politics: Discourse and Democracy in A Divided World; Polity Press: Cambridge, UK, 2006.

58. The Peoples Health Movement. The People's Health Movement: A People's Campaign for Health for All-Now! Peoples Health Movement, 2006. Available online: http://www.phmovement.org/en/node/189 (accessed on 10 September 2011).

59. Global Health Watch, Homepage. Available online: http://www.ghwatch.org/ (accessed on 13 December 2011)

60. Cohen, E.R.M.; Hassan, M.; Berndston, K.; Saunders, V.; Hadfield, T.; Panjwani, D.; Persad, D.L.; Minhas, G.S.; Daar, A.S.; Sing, J.A.; Singer, P.A. Public engagement on global health challenges. BMC Public Health 2008, 8, 1-8.

61. Fishkin, J.S. Response to critics of when the people speak: The deliberative deficit and what to do about it. Good Soc. J. 2010, 19, 68-76.

62. Baber, W.F.; Bartlett, R.V. Deliberative Environmental Politics: Democracy and Ecological Rationality; The MIT Press: Cambridge, MA, USA, 2005.

63. David, A.; Esson, K.; Perucic, A.; Fitzpatrick, C. Tobacco Use: Equity and Social Determinants. In Equity, Social Determinants and Public Health Programmes; Blas, E., Kurup, A.S., Eds.; World Health Organisation: Geneva, Switzerland, 2010; pp. 199-218

64. Hansen, K.M.; Anderson, V.N. Deliberative democracy and the deliberative poll on the euro. Scand. Polit. Stud. 2004, 27, 261-286.

65. He, B.; Thorgerson, S. Giving the people a voice? Experiments with consultative authoritative experiments in China. J. Contemp. China 2010, 19, 675-692.

66. Yankelovich, D.; Rosell, S.; Gantwerk, H.; Friedman, W. The next big step in deliberative democracy. Kettering Rev. 2006, Fall, 54-66.

67. Americaspeaks. Public Impacts: Evaluating the Outcomes of the CaliforniaSpeaks Statewide Conversation on Health Care Reform; Americaspeaks: Washington, DC, USA, N.D. Available online: http://californiaspeaks.org/wpcontent/_data/n_0002/resources/live/CaSpks\%20Evaluation \%20Report.pdf (accessed on 4 March 2012).

68. Fung, A.; Taeku, L. The Difference Deliberation Makes: A Report on the CaliforniaSpeaks Statewide Conversations on Health Care Reform; Californiaspeaks: 2008. Available online: http://archonfung.net/docs/reports/CASpeaksReportFinalv3.pdf (accessed on 4 March 2012).

69. CaliforniaSpeaks: The Public Weighs in on Current Health Care Reform Proposals; Americaspeaks: Washington, DC, USA, N.D. Available online: http://ckgroup.org/wpcontent/uploads/2011/05/CA-Speaks-Report.pdf (accessed on 4 March 2012). 
70. Commers, M. Determinants of Health: Theory, Understanding, Portrayal, Policy; Kluwer Academic: Dordrecht, The Netherlands, 2002.

71. Hooker, C.; Chapman, S. Deliberately personal: Tobacco control debates and deliberative democracy in New South Wales. Crit. Public Health 2006, 16, 35-46.

72. Brown, G.W. Safeguarding deliberative global governance: The case of the global fund to fight AIDS, tuberculosis and malaria. Rev. Int. Stud. 2010, 36, 511-530.

73. Harman, S. The World Bank and HIV/AIDS: Setting a Global Agenda; Routledge: London, UK, 2010.

74. Drager, N.; Sunderland, L. Governance and Moving Forward the Global Health Agenda: A Perspective from the World Health Organization. In Proceedings of the Annual Convention of the International Studies Association (ISA), Chicago, IL, USA, 28 February-2 March 2007; pp. 1-9.

75. Legge, D. Global Health Governance-The Need for Democratic Reform. In Proceedings of the Global Health Governance Reform Initiative, Geneva, Switzerland, 14-15 May 2010.

76. Kickbusch, I.; Hein, W.; Silberschmidt, G. Addressing global health governance challenges through a new mechanism: The proposal for a Committee $\mathrm{C}$ of the World Health Assembly. Glob. Health Gov. 2010, Fall, 550-563.

(C) 2012 by the authors; licensee MDPI, Basel, Switzerland. This article is an open-access article distributed under the terms and conditions of the Creative Commons Attribution license (http://creativecommons.org/licenses/by/3.0/) 